\title{
Tracking of Vehicle Tax Violations Using Vehicle Type and Plate Number Identification
}

\author{
Arsan Kumala Jaya ${ }^{1}$, Zahir Zainuddin ${ }^{2}$, Syafruddin Syarif ${ }^{3}$ \\ 1,2,3 Department of Electrical Engineering, Faculty of Engineering, Universitas Hasanuddin \\ Makassar, Indonesia, 92119 \\ \{jayaak17d@student.unhas.ac.id ${ }^{1}$,zahir@unhas.ac.id², syafruddin.s@eng.unhas.ac.id ${ }^{3}$ \}
}

\begin{abstract}
This paper describes tracking violations of vehicle tax using the identification of type and number plates on vehicles. The case study of this research is in Sulawesi Selatan (Indonesia). The Gaussian Mixture Model (GMM) algorithm is used to detect vehicle types and the Automatic Number Plate Recognition (ANPR) algorithm for detecting vehicle license numbers. The proposed system uses a digital camera with a camera height of $250 \mathrm{~cm}$ and a camera tilt angle of 55 degrees. The proposed system design is the stages of preprocessing, feature extraction, feature selection, model selection, and database. For the introduction of types of vehicles are classified based on predetermined ROI while the introduction of vehicle numbers is trained using k-Nearest Neighbor $(\mathrm{KNN})$. The results of the proposed system accuracy are $91 \%$ for vehicle type detection and $70 \%$ for vehicle license number detection.
\end{abstract}

Keywords: Vehicle Tax, Vehicle Type, Number Plate, GMM, ANPR, KNN.

\section{Introduction}

Vehicle Tax is a tax on the ownership and/or control of motorized vehicles for the purpose of building an area [1]. Based on data from Badan Pendapatan Daerah, the number of vehicles in arrears of taxes increased to $43 \%$ of the number of vehicles registered. The case study of this research is in Sulawesi Selatan (Indonesia). An increase in the number of tax arrears has an effect on traffic violations because they cannot show a vehicle registration certificate that has been approved [2]. Along with the increase in the number of vehicle tax takers, vehicle tax information will be needed to find out vehicles that have not paid taxes.

The development of information and communication technology to obtain information on motorized vehicle traffic will increase. In India, Krishna et al. monitor vehicle traffic using computer vision. The system proposed has an accuracy of $98,96 \%$ for vehicle count detection and $98,14 \%$ for speed violation detection [3]. Deng and Yang researched monitoring of motorcycle violations by analyzing motorcycle traffic. The researcher used the Bisecting Kmeans algorithm to classify the analysis of all road segments [4]. In Thailand, Klubsuwan et al. Evaluated the vehicle traffic behavior using the Mean Square Displacement (MSD) algorithm for red light violations and changes in traffic lanes. As a result, with the algorithm, the researcher gets high accuracy [5].

In this paper, the author will track vehicle tax violation using the type and number plate on motorized vehicles. Research related to the detection of vehicle types has been carried out by 
researchers. In [6], Indrabayu et al. used the Gaussian Mixture Model (GMM) method for vehicle detection and Kalman Filter for object tracking. Researchers used the Region of Interest (ROI) from vehicle features for car and motorbike classifications. The test results get $97.22 \%$ accuracy for light traffic conditions, $79.63 \%$ accuracy for heavy traffic conditions and $100 \%$ accuracy for the consistency of average object tracking. In [7], Nilakorn et al. used the GMM algorithm for vehicle detection and the k-NN algorithm for vehicle classification. This research uses three classification categories namely small-size (bicycle, motorcycle), mid-size (car, van, small truck), and large-size (big truck, bus). The test results get the accuracy of the detection and classification of vehicles $98.53 \%$.

In research related to vehicle plate number detection, Achmad et al. used the Image Processing technique on vehicle number plate images to obtain vehicle information. Vehicle number plate identification uses Optical Character Recognition (OCR) and Automatic Number Plate Recognition (ANPR). In vehicle classification, researchers use the Learning Vector Quantization (LVQ) method. The results of the introduction of vehicle license numbers will be sent on the Jakarta Samsat website to obtain motor vehicle tax information. The test results for vehicle plate number detection get an accuracy of 95.32\% [8]. However, this research uses still vehicle images for detection of plate numbers. In [9], Riza et al. found a solution for plate detection in moving vehicles using edge optimization techniques and contour detection of vehicle plates. The test results reached an accuracy of $96.67 \%$

Tracking vehicle tax violations in Kabupaten Gowa still use manual methods. Tax officers use manual checking of Vehicle Registration Certificate (VRC) to find out the VRC that is past due. This method causes congestion during a vehicle tax audit operation on the highway because of the accumulation of vehicles during the inspection process. Therefore, tax officers need to monitor motor vehicle tax violations to improve vehicle identification processes. Tracking vehicles using computer vision technology can be a solution to reduce vehicle tax violations on the highway. The author uses cameras to increase efficiency and reduce dependence on human power.

\section{Proposed Method}

In this paper, the authors propose the type and plate number identification can be used to detect motor vehicle tax violations. In vehicle type, Object detection and classification are two crucial image processing tasks because each object has its unique features. The object detection provides information about localization of the object while object classification offers information about category the object [10]. Vehicle types were identified using the Gaussian Mixture Model (GMM). GMM is a robust method for dynamic backgrounds [11]. The advantage of the GMM algorithm can show multi-mode changes in pixel values, account lighting changes, repetitive space movements and scene changes in real time [12], [13]. The Automatic Number Plate Recognition (ANPR) method is a method proposed to Identification Vehicle Number. In generally, ANPR distributed into detection part and recognition part [14].

The identification process begins with taking video data through camera. This research uses the video data stream as input data. The author uses a digital camera with a specification 1.3 MegaPixel HD 960P resolution. Video data on vehicle traffic is taken directly on the side of the road in Kabupaten Gowa, Sulawesi Selatan, Indonesia. Height of the camera is $250 \mathrm{~cm}$, and the camera's tilt angle is 55 degrees towards the vehicle. Fig. 1. Show scenario for taking video traffic of vehicle traffic. 


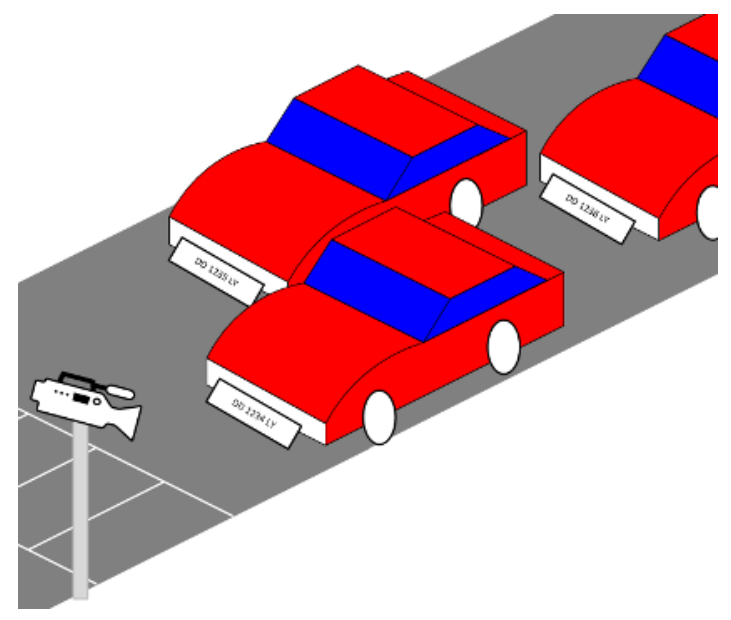

Fig. 1. Data Retrieval Scenario

The video data stream is processed with image processing techniques with several stages, namely pre-processing, feature extraction, feature selection, model selection, and database.

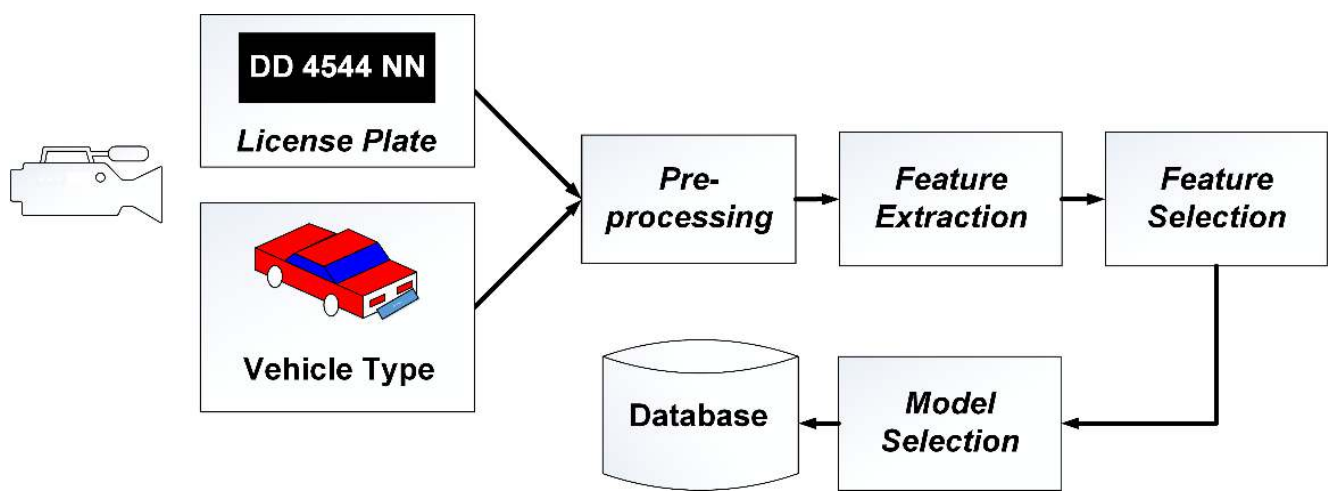

Fig. 2. General System Design

The author identifies vehicles that violate using two parameters as data acquisition. They are the vehicle plate number and type of vehicle to get a sophisticated and real vehicle identity. Following is the process of the general design proposed.

\subsection{Pre-processing}

Pre-processing is the initial segmentation process used to eliminate noise, filtering, normalization, and release of outliers. In the type of vehicle, the steps taken are Denoise process, changing the RGB color frame to grayscale and threshold. The denoise process aims to reduce noise in the frame by using the Median Blur and Gaussian Blur from computer vision. RGB to Grayscale aims to reduce the color value of the frame. Grayscale to threshold values for 1 and 0 . This value will be used to determine the foreground and background on the frame. 


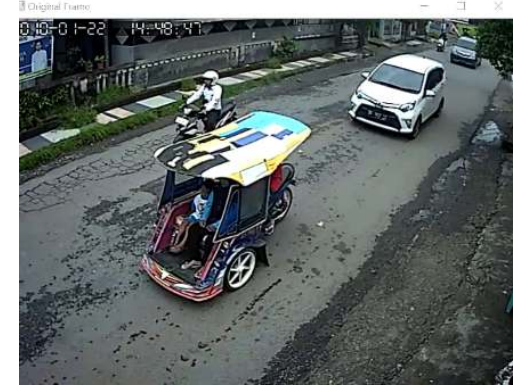

(a)

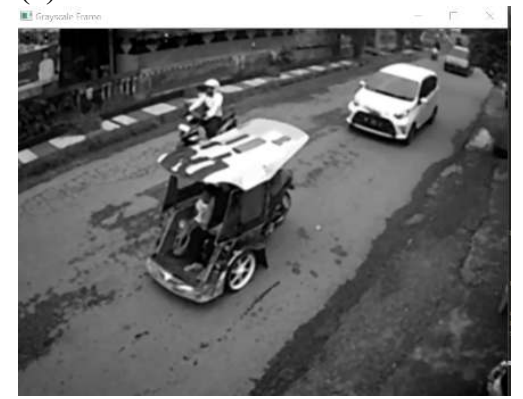

(c)

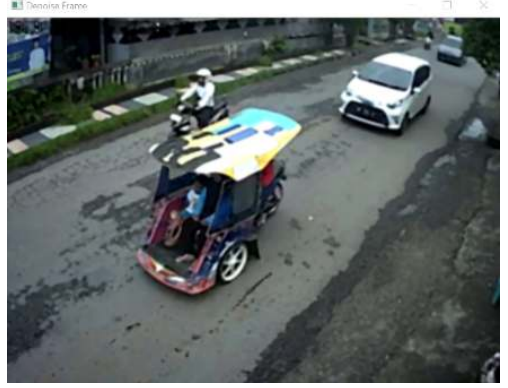

(b)

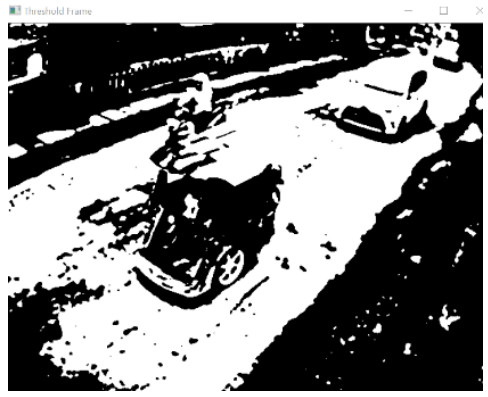

(d)

Fig. 3. Pre-processing vehicle type : (a) original frame, (b) blurred frame, (c) grayscale, (d) threshold

Pre-processing on the plate number is to change the color frame (RGB) to grayscale, threshold, median filtering, segmentation, and normalization. Median filtering functions to smooth and reduce noise or interference with the image. Image segmentation is to cut the image of each character. Cropping images using Blob detection in order to determine whether a group of pixels is connected to each other. Image normalization is to set each character size $6 \times 8$ so that all sizes become one and the same size.

\section{DD 2321 BK}

(a)

\section{DO $2321 \mathrm{BK}$}

(c)

\section{DD $2321 \mathrm{BK}$}

(b)

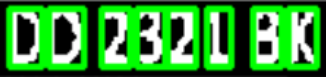

(d) 
Fig. 4. Pre-processing plate number : (a) grayscale, (b) threshold, (c) median filtering, (d) image segmentation

\subsection{Feature Extraction}

The feature extraction is used to get the characteristics of the vehicle type and vehicle license number. Changes to pixels will be changed to 1 for black and -1 for white before inputting to an array variable. While the type of vehicle uses the GMM algorithm for feature extraction from vehicles. GMM, with the master estimating a distribution of good solutions in the search space as a set of the cluster, assumes that good solutions in each cluster follow a Gaussian distribution [15], [16]. GMM will accumulate a Gaussian distribution to estimate pixel density in each frame. The goal is to get a background update model. Reducing background is the first step in the method proposed to detect moving vehicles in each frame. GMM, it can be expressed in equation 1

$$
\left\{\mathrm{X}_{1}, \ldots, \mathrm{X}_{\mathrm{t}}\right\}=\left\{\mathrm{I}\left(\mathrm{X}_{0}, \mathrm{y}_{0}, \mathrm{i}\right): 1 \leq \mathrm{i} \leq \mathrm{t}\right\}
$$

At GMM, the Gaussian $\mathrm{K}$ distribution is used to represent pixel history values. So, the equation is :

$$
\mathrm{P}\left(\mathrm{X}_{\mathrm{i}}\right)=\omega_{\mathrm{i}, \mathrm{t}} \eta \sum_{\mathrm{i}=1}^{\mathrm{k}}\left(\mathrm{X}_{\mathrm{i}}, \mu_{\mathrm{i}, \mathrm{t}}, \sum_{\mathrm{i}, \mathrm{t}}\right)
$$

Where $\omega_{i, t}$ is the approximate of weight $i^{\text {th }}$ at time $t, \mu_{i, t}$ : is the average value at time $t$, and $\sum_{\mathrm{i}, \mathrm{t}}$ is the ith covariance matrix at time $\mathrm{t}$.

Fig. 5. The following results from feature extraction in

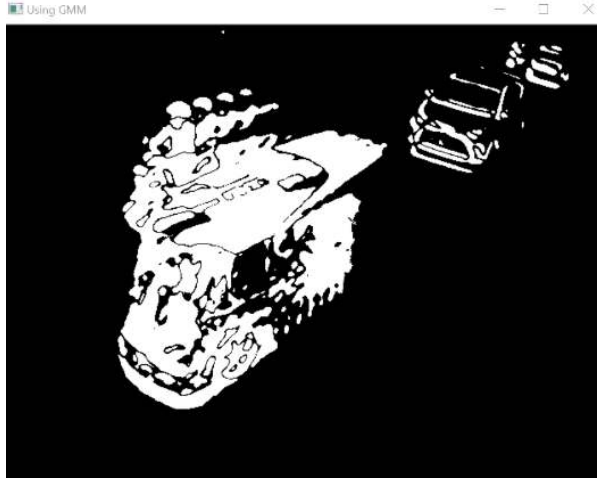

(a)

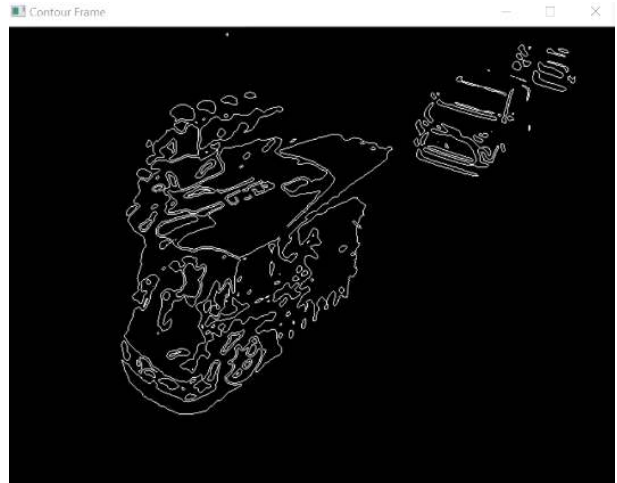

(b)

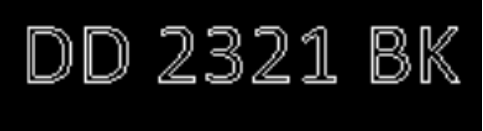

(c) 
Fig. 5. Feature extraction : (a) frame GMM, (b) contour GMM of vehicle, (c) contour of number plate

\subsection{Feature Selection}

In the type of vehicle, object contours are used as features that will be selected for classification. The feature value of the object contour is the width, height, and area as shown in Fig. 5 section (b). Whereas in the vehicle plate number, the contours of each character that has been normalized will be carried out by the process of finding the closest weight value to the dataset of trained characters.

\subsection{Model Selection}

In this paper, the authors propose the k-Nearest Neighbor (k-NN) algorithm to classify characters from vehicle number plates. The k-NN algorithm is an algorithm that looks for groups of $\mathrm{k}$ objects in training data closest to objects in new data or testing data. The number of characters in the dataset is 36 characters. Where characters (A-Z) number 26 and characters $(0$ 9) number 10.

In [17], [18], Euclidean Distance is used to determine the distance between two training and testing objects. Number plate characters that have been detected will be recognized by looking for the closest weight value from the dataset using equation (3).

$$
d x y=\sqrt{\sum_{t=1}^{a}\left(x_{i}-y_{i}\right)}
$$

Where dxy is the distance $x y, x$ is the dataset value and $y$ is the target value.

\subsection{Database}

MySQL database is used to search vehicle identity data including vehicles that have not reregistered the vehicle tax. Following are vehicle tax data in the database. 


\begin{tabular}{|c|c|c|c|c|c|c|c|c|c|}
\hline nopol & nama & alamat & tgmslaku & pkbpokok & pkbdenda_t $t$ & pkbpokok_t & nacamat & nadesa & \\
\hline DD8013LY Y & MARDIYATI & KUTULU KAB GOWA & 2016-01-16 & 1716000 & 1269840 & 6864000 & BAJENG & MATA ALLLO & TRUCK \\
\hline D01053BA & $\begin{array}{l}\text { H.ABD.RASYID } \\
\text { SITUDJU }\end{array}$ & $\begin{array}{l}\text { MANANNANG } \\
\text { KELLIIMBUNG KEC } \\
\text { BAJENG KAB.GOWA }\end{array}$ & $2012-01-31$ & 614250 & 1019655 & 3685500 & BAJENG & LIMBUNG & MINIBUS \\
\hline DD8226LZ & H MUH DARWIS & TANETEA GOWA & 2018-01-12 & 3276000 & 851760 & 6552000 & BAJENG & BONTOSUNGGU & $\begin{array}{l}\text { LIGHT } \\
\text { TRUCK } \\
\text { BAK }\end{array}$ \\
\hline DD8224LB & HAKIB & $\begin{array}{l}\text { BONTOBILA } \\
\text { TUBAENG BAJENG } \\
\text { KAB GOWA }\end{array}$ & $2018-01-30$ & 3217500 & 772200 & 6435000 & BAJENG & TUBAJENG & $\begin{array}{l}\text { LIGHT } \\
\text { TRUCKI } \\
\text { BAK }\end{array}$ \\
\hline DD1459BF & M JAFFAR & $\begin{array}{l}\text { BONTO TANGNGA } \\
\text { GOWA }\end{array}$ & 2014-01-31 & 615000 & 725700 & 3690000 & BAJENG & BONTOSUNGGU & SEDAN \\
\hline D08371La & JUANDI & $\begin{array}{l}\text { DOJA KECB.BAJENG } \\
\text { KAB.GOWA }\end{array}$ & $2016-01-08$ & 877500 & 649350 & 3510000 & BA.JENG & TANGKEBAJENG & $\begin{array}{l}\text { LIGHT } \\
\text { TRUCKI } \\
\text { BAK }\end{array}$ \\
\hline DD1211LZ & $\begin{array}{l}\text { DRS.H.AKHMAD } \\
\text { SAKTI }\end{array}$ & $\begin{array}{l}\text { TIMPOPPO } \\
\text { KAB.GOWA }\end{array}$ & 2017-01-29 & 1323000 & 635040 & 3969000 & BAJENG & MATA ALLO & MINIBUS \\
\hline D01033BE & SABIR.H.M & $\begin{array}{l}\text { PANCIRO RT.01/RW.02 } \\
\text { KEC. BANENG } \\
\text { KAB.GOWA }\end{array}$ & 2013-01-31 & 425250 & 603855 & 2551500 & BAJENG & PANCIRO & JEEP \\
\hline DD5491BU & ABRAR ZAINAL & PAKKINGKINGANG & $2011-01-21$ & 300000 & 576000 & 1800000 & BAJENG & MACCINIBA.II & SPDMOTOR \\
\hline DO9452BN & SYAHRIR & $\begin{array}{l}\text { KALEBAJENG } \\
\text { KEC BAJENG KAB } \\
\text { GOWA }\end{array}$ & 2013-01-31 & 370500 & 526110 & 2223000 & BAJENG & TANGKEBAJENG & $\begin{array}{l}\text { LIGHT } \\
\text { TRUCK, } \\
\text { BAK }\end{array}$ \\
\hline
\end{tabular}

Fig. 6. Database of Vehicle Tax

In Fig. 6 there is a column of the number plate, vehicle type, and due date. it will be used as parameters for finding data on the introduction of vehicles based on the type and number of vehicle plates.

\section{Results and Discussion}

Detecting the type of vehicle using contours as a result of the separation of the background is then given a limit on ROI. For this type of vehicle (Roda 4) uses a contour with a value of width $>220$ and a height value of $>100$. Whereas the type of motorbike vehicle (Roda 2 ) uses a contour with a width $<221$ and height $>100$. area $<5000$. Based on the equation in [6], the accuracy value of the type of vehicle can be seen in Table 1 .

Table 1. Type Vehicle Accuracy

\begin{tabular}{llll|lll}
\hline \multirow{2}{*}{ Data } & Roda 2 & \multicolumn{5}{c}{ Roda 4 } \\
\cline { 2 - 7 } & Actual & System & Acc & Actual & System & Acc \\
\hline 1 & 28 & 24 & $86 \%$ & 13 & 12 & $92 \%$ \\
2 & 31 & 29 & $94 \%$ & 15 & 12 & $80 \%$ \\
3 & 23 & 21 & $91 \%$ & 9 & 9 & $100 \%$ \\
4 & 35 & 32 & $91 \%$ & 11 & 10 & $91 \%$ \\
5 & 27 & 35 & $93 \%$ & 10 & 9 & $90 \%$ \\
Avg & & & $91 \%$ & & & $91 \%$ \\
\hline
\end{tabular}

Table 1 has an average value of detection of motorbike and car type detection is $91 \%$. Meanwhile, based on the equation in [8], the accuracy value of vehicle license plate testing can be seen in Table 2 . 
Table 2. License Plate Accuracy

\begin{tabular}{llll}
\hline Data & Actual & System & Acc \\
\hline 1 & DD1179VG & DD111V & $63 \%$ \\
2 & DD1923YV & DD93Y & $63 \%$ \\
3 & DD3121NB & DD121N & $63 \%$ \\
4 & DD1010LU & DD1010 & $75 \%$ \\
5 & DD3452LJ & DD345 & $63 \%$ \\
6 & DD17UZ & DD17U & $83 \%$ \\
7 & DD1852BY & DD182 & $63 \%$ \\
8 & DD1335DN & D133SDN & $88 \%$ \\
9 & B1610PTK & 10PKK & $63 \%$ \\
10 & B1418NJK & B141NIK & $75 \%$ \\
Avg & & & $70 \%$ \\
\hline
\end{tabular}

The average yield accuracy of vehicle plate recognition is $70 \%$. The following are the results of the detection of vehicle tax violations.

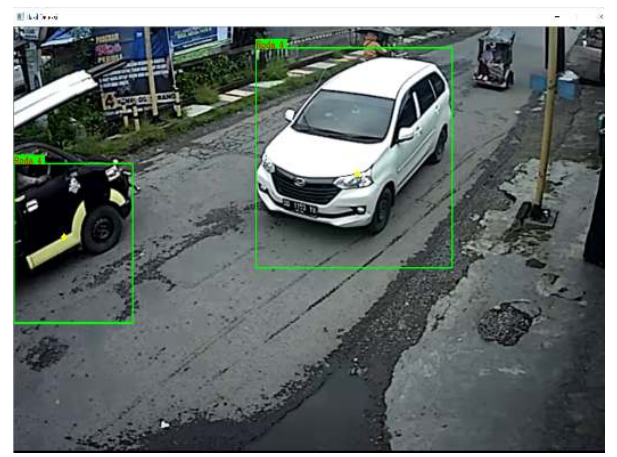

(a)

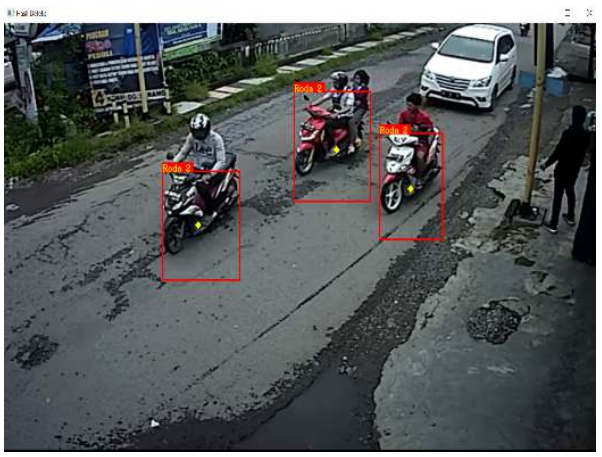

(b)

Fig. 7. Detection results of vehicle types: (a) Car detection, (b) Motor Detection

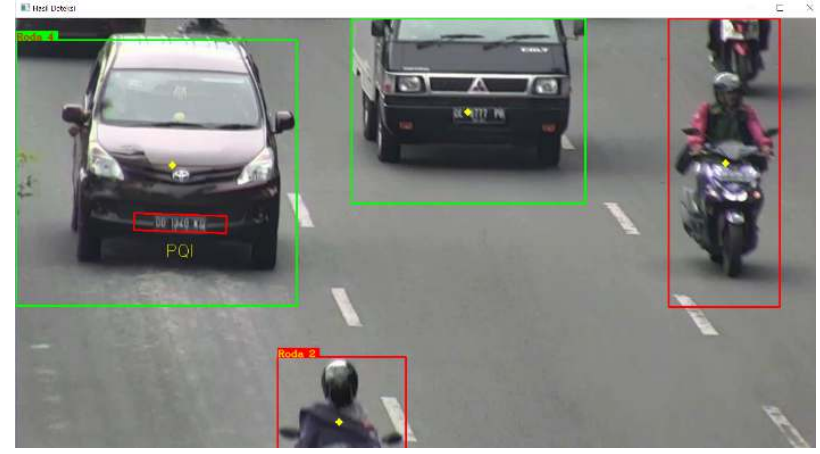


Fig. 8. Detection results of plate number

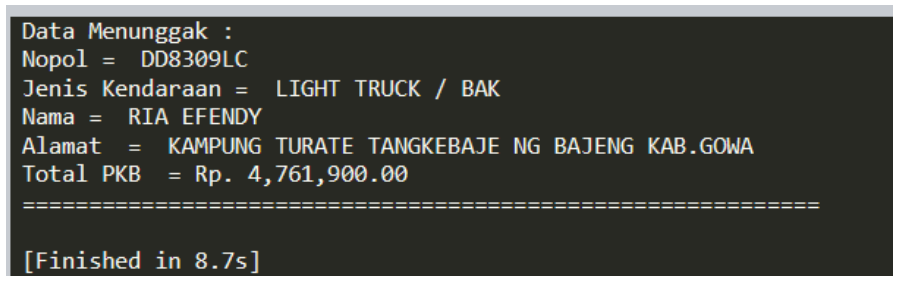

Fig. 9. Results of detection of violating vehicles

On vehicle tracking that violates, the camera calibration technique is very influential to get vehicle type information and vehicle plate numbers. The camera height and camera tilt angle are parameters that can be measured for the success of vehicle data to be recognized.

\section{Conclusion}

This research uses real-time data on Highway. Retrieving data using a digital camera with a resolution of 1280x960 with a camera height of $250 \mathrm{~cm}$ and a tilt angle of the camera 55 degrees facing the vehicle. Vehicle type and vehicle license number are used as input parameters to obtain information on vehicles that violate motor vehicle tax. The vehicle type detection method uses the GMM algorithm and vehicle classification determination with predetermined ROI limits and plate detection using ANPR with the introduction of vehicle plate numbers using the k-NN algorithm. The test results by comparing manual observations and using the system, vehicle type tracking testing get an accuracy of $91 \%$ and vehicle plate number detection tests get $70 \%$ accuracy.

\section{References}

[1] P. P. SULAWESI SELATAN: PERATURAN DAERAH PROVINSI SULAWESI SELATAN NOMOR 10 TAHUN 2010 TENTANG PAJAK DAERAH. Indonesia, (2010).

[2] P. R. INDONESIA: UNDANG-UNDANG NOMOR 22 TAHUN 2009 TENTANG LALU LINTAS DAN ANGKUTAN JALAN. (2009).

[3] Krishna, M. Poddar, M. K. Giridhar, A. S. Prabhu, and V. Umadevi: "Automated traffic monitoring system using computer vision," in Proceedings of 2016 International Conference on ICT in Business, Industry, and Government, ICTBIG 2016, doi :10.1109/ICTBIG.2016.7892717, (2016).

[4] Y. Deng and H. Yang: "Motorcycle traffic violation analysis and selection of key road sections for monitoring in Guangzhou," in 2017 4th International Conference on Transportation Information and Safety, ICTIS 2017 - Proceedings, pp. 1122-1127, doi :10.1109/ICTIS.2017.8047911, (2017).

[5] K. Klubsuwan, W. Koodtalang, and S. Mungsing: "Traffic violation detection using multiple trajectories evaluation of vehicles," in Proceedings - International Conference on Intelligent Systems, Modelling and Simulation, ISMS, pp. 220-224, doi :10.1109/ISMS.2013.143, (2013).

[6] Basri, Indrabayu, and A. Achmad: "Gaussian Mixture Models optimization for counting the numbers of vehicle by adjusting the Region of Interest under heavy traffic condition," in 2015 International Seminar on Intelligent Technology and Its Applications, ISITIA 2015 - Proceeding, pp. 245-249, doi :10.1109/ISITIA.2015.7219986, (2015). 
[7] N. Seenouvong, U. Watchareeruetai, C. Nuthong, K. Khongsomboon, and N. Ohnishi: "Vehicle detection and classification system based on virtual detection zone," in 2016 13th International Joint Conference on Computer Science and Software Engineering, JCSSE 2016, doi :10.1109/JCSSE.2016.7748886, (2016).

[8] A. Solichin and Z. Rahman: "Identifikasi Plat Nomor Kendaraan Berbasis Mobile dengan Metode Learning Vector Quantization,” J. TICOM, vol. 3, no. 3, pp. 1-7, (2015).

[9] A. R. F. Quiros et al.: "Localization of license plates using optimized edge and contour detection technique," in IEEE Region 10 Annual International Conference, Proceedings/TENCON, vol. 2017-Decem, pp. 1075-1080, doi :10.1109/TENCON.2017.8228017, (2017).

[10] S. Kul, S. Eken, and A. Sayar: "A concise review on vehicle detection and classification," in Proceedings of 2017 International Conference on Engineering and Technology, ICET 2017, pp. 1-4, doi :10.1109/ICEngTechnol.2017.8308199, (2018).

[11] S. T. Ali, K. Goyal, and J. Singhai: "Moving object detection using self adaptive Gaussian Mixture Model for real time applications," in International Conference on Recent Innovations in Signal Processing and Embedded Systems, RISE 2017, pp. 153-156, doi :10.1109/RISE.2017.8378144, (2018).

[12] H. Wang, J. Gao, L. Yu, Y. Hu, and Z. Wang: "Combined improved Frequency-Tuned with GMM algorithm for moving target detection," in 2017 IEEE International Conference on Mechatronics and Automation, ICMA 2017, pp. 1848-1852, doi :10.1109/ICMA.2017.8016099, (2017).

[13] L. Mabrouk, D. Houzet, S. Huet, S. Belkouch, A. Hamzaoui, and Y. Zennayi: "Single Core SIMD Parallelization of GMM Background Subtraction Algorithm for Vehicles Detection," Colloq. Inf. Sci. Technol. Cist, vol. 2018-Octob, pp. 308-312, doi : 10.1109/CIST.2018.8596385, (2018).

[14] S. A. Haider and K. Khurshid: "An implementable system for detection and recognition of license plates in Pakistan," in ICIEECT 2017 - International Conference on Innovations in Electrical Engineering and Computational Technologies 2017, Proceedings, doi :10.1109/ICIEECT.2017.7916553, (2017).

[15] "Gaussian Mixture Model | Brilliant Math \&amp; Science Wiki." [Online]. Available: https://brilliant.org/wiki/gaussian-mixture-model/. [Accessed: 18-Apr-2019].

[16] S. Syarif, Syafaruddin, Wardi, and S. Kobayashi: "Quality Analysis and Illegal Logging Image Detection using Syaritar Method," Int. J. Innov., vol. 11, no. 3, pp. 1093-1099, (2015).

[17] Okfalisa, I. Gazalba, Mustakim, and N. G. I. Reza: "Comparative analysis of k-nearest neighbor and modified k-nearest neighbor algorithm for data classification," in Proceedings - 2017 2nd International Conferences on Information Technology, Information Systems and Electrical Engineering, ICITISEE 2017, vol. 2018-Janua, pp. 294-298, doi :10.1109/ICITISEE.2017.8285514, (2018).

[18] "Cara Kerja Algoritma k-Nearest Neighbor (k-NN) - Bee Solution Partners - Medium." [Online]. Available: https://medium.com/bee-solution-partners/cara-kerja-algoritma-knearest-neighbor-k-nn-389297de543e. [Accessed: 18-Apr-2019]. 